\title{
Low-Cost sensors for urban air quality monitoring: preliminary laboratory and in-field tests within the TECNAIRE-CM project
}

\author{
Begoña Artíñano \\ b.artinano@ciemat.es \\ Francisco Javier Gómez \\ fj.gomez@ciemat.es
}

\author{
Adolfo Narros \\ adolfo.narros@upm.es \\ Rafael Borge \\ I \\ rafael.borge@upm.es
}

Elías Díaz
elias.diaz@ciemat.es

\begin{abstract}
Low-cost sensor technology can potentially make revolutionary changes in our current air pollution monitoring paradigm in urban areas. However, the widespread adoption of low-cost sensor technology is still not feasible due to a number of limitations regarding sensitivity, accuracy and comparability. In this study we report the results from preliminary laboratory and in-field tests carried out within the TECNAIRE-CM project for commercial $\mathrm{NO}_{2}$ and $\mathrm{O}_{3}$ sensors including both, solid-state and electrochemical technologies. The ultimate goal is to understand the current capabilities of this technology and the prospects to incorporate it in both research and routine measurement or urban air quality. We found significant performance differences although none of the devices tested could provide satisfactory results in real-world conditions. We conclude that unit-specific advanced statistical calibration methods are needed to obtain reliable results with the low cost sensors devices in urban areas.
\end{abstract}

Keywords-air quality, low cost sensors, linear regression, multivariate linear regression, artificial neural networks

\section{INTRODUCTION}

Air quality networks currently used for monitoring air quality in urban environments use standardized methods, defined in the Air Quality Directive [1], that provide reliable and comparable data. However, due to its complexity and cost it is only possible to measure at very specific points and the concentration data provided may be influenced by micro-location conditions making it difficult to assess the spatio-temporal representativeness of the observation. This is particularly true in urban areas, where strong spatial and temporal concentration variations exist [2].

Low-cost sensor technology can potentially make revolutionary changes in the area of air pollution monitoring by providing high density spatiotemporal pollution data. Such data can be used for supplementing traditional pollution monitoring, improving exposure estimates, and raising community awareness about air pollution. The use of low-cost gas sensors for monitoring ambient air pollution would reduce air pollution monitoring costs and would also allow larger spatial coverage. This holds great promise both for cities [3] and remote areas where monitoring with traditional facilities is cumbersome [4]. However, the calibration of low-cost sensors for monitoring air quality remains a challenge. The selectivity and stability of sensors are generally found problematic [5-7] and seriously hinders the widespread adoption of low-cost sensor technology [8].

In this study, the performance of commercially available low-cost sensors has been evaluated using laboratory tests and also a real-time field calibration in a co-location experiment carried out in an air quality station of the Madrid City Council Air Quality Network. This corresponds to the early-stage research carried out in the TECNAIRE-CM project to understand the current capabilities of this technology and the prospects to incorporate it in both research and routine measurement or urban air quality.

\section{METHODOLOGY}

\section{A. Instrumentation and experimental design of laboratory tests}

Several laboratory tests were performed to assess the behavior of selected sensors under controlled conditions. Three models, Libelium WaspMote, Libelium Waspmote Plug \& Play and Aeroqual Series 500, were monitored within an ad-hoc designed chamber in the laboratory (Fig. $1)$. The devices were provided by some companies involved in the project that deem them as representative of different commercial products already available in the market.

The Libelium Waspmote sensor provides $\mathrm{NO}_{2}$, and $\mathrm{O}_{3}$ concentrations as well as complementary parameters such as relative humidity, temperature, and pressure with solidstate technology. The Libelium Waspmote Plug\&Play sensor provides the same parameters using 
electrochemical cells for the gases analysis. The Aeroqual sensor gives $\mathrm{NO}_{2}$ concentrations by means of an electrochemical cell and active flow.

The designed chamber allowed temperature control thus three points were used: 15,25 and $35^{\circ} \mathrm{C}$, while relative humidity was only monitored. The response of the sensors to prefixed concentrations of $\mathrm{NO}_{2}$ and $\mathrm{O}_{3}$ generated from a certified bottle of NO was examined. The system for reference values generation is shown in Fig. 1. Reference concentrations for $\mathrm{NO}_{2}$ and $\mathrm{O}_{3}$ were measured by TECO-42 and Thermo Environmental calibrated instruments, respectively.

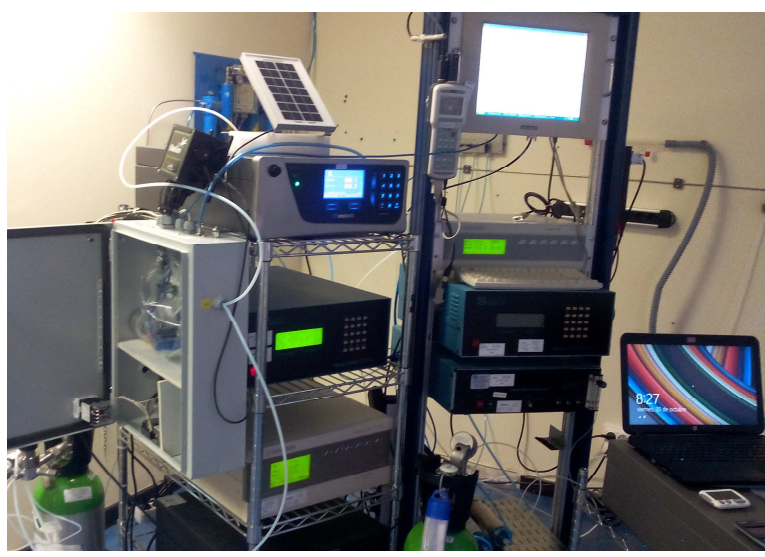

Fig. 1. Complete system for the test of reference gases, relative humidity and temperature

A stability test was performed by adjusting during two hours at span concentration, and $48 \mathrm{~h}$ at zero concentration. The repeatability exercise consisted of low/high point ( $50 \mathrm{ppb} / 400 \mathrm{ppb}$ ) calibrations for $4 \mathrm{~h}$ with a 20 minute sequence. Finally, linearity was assessed by means of a 5-point calibration in the $0-400 \mathrm{ppb}$ range for $\mathrm{NO}_{2}$ and $0-200 \mathrm{ppb}$ for $\mathrm{O}_{3}$.

\section{B. In field co-location tests}

Three commercial low-cost sensing devices (made freely available by the corresponding manufacturers) were simultaneously collocated in the Fernandez Ladreda (FL) Air Quality Station, a traffic station located in an urban pollution hot-spot [2] that provided 1-hour resolution $\mathrm{NO}_{2}$ and $\mathrm{O}_{3}$ concentration levels based on reference measuring techniques.

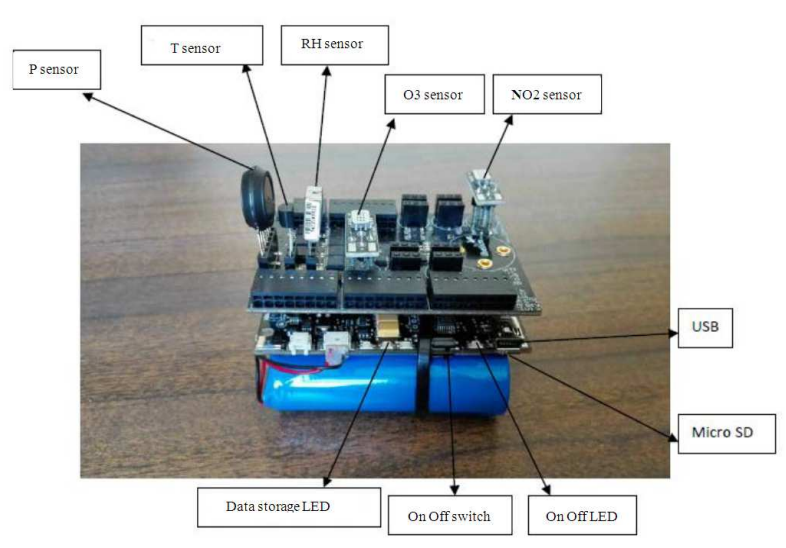

Fig.2. Libelium Waspmote

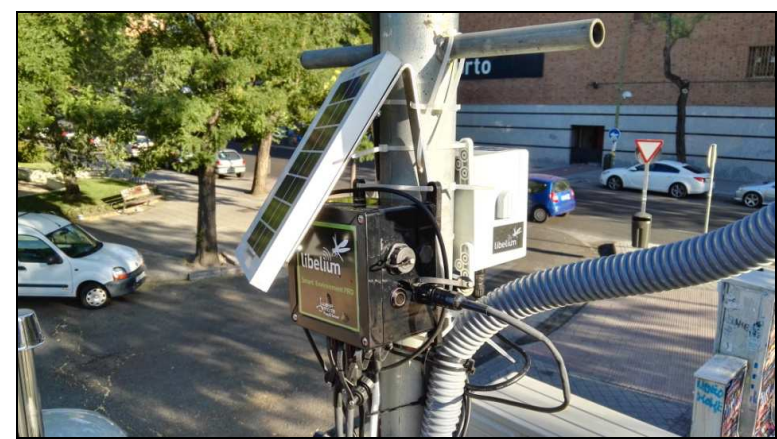

Fig.3. Libelium Plug and Sense

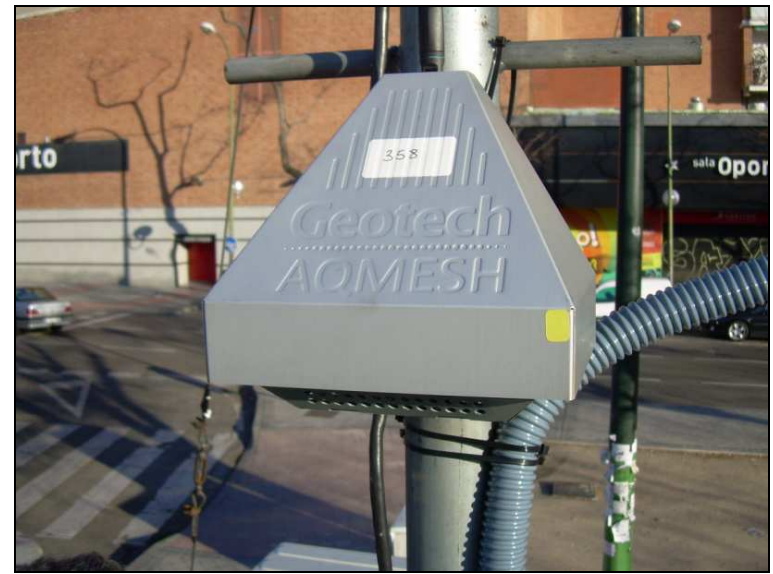

Fig.4. Geotech AQmesh

Besides temperature, relative humidity and atmospheric pressure, the Libelium Waspmote device (Fig. 2) was fitted with two metal oxide sensors, the MICS 2714 for $\mathrm{NO}_{2}$ and the MICS 2614 for $\mathrm{O}_{3}$. Measured data were stored in a built in SD card. The Libelium Plug and Sense device (Fig. 3) has $\mathrm{NO}_{2}$ and $\mathrm{O}_{3}$ Alphasense electrochemical sensors along with meteorological sensors, and the information was sent via 4G to our server. Finally, the AQmesh device (Fig. 4) has also Alphasense $\mathrm{NO}_{2}$ and $\mathrm{O}_{3}$ electrochemical sensors and the data were sent via $4 \mathrm{G}$ to a server in the UK. The raw data were treated by a proprietary algorithm and later downloaded as corrected data.

\section{RESULTS}

\section{A. Laboratory tests}

Fig. 5 shows the results of the Libelium sensors test for ozone concentrations. The Waspmote Plug and Sense device showed no sensibility for ozone whereas the Waspmote, based on solid-state technology was specific, with a sensibility of 5 times lower than reference values. This method could be used with new calibration factors.

However, the equipment has shown a slight sensitivity to nitrogen dioxide, indicating a lack of specificity, but not very significant. 


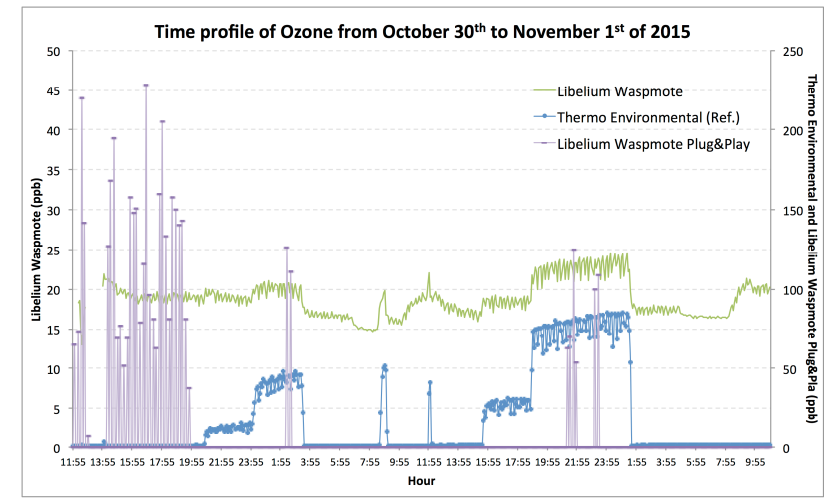

Fig.5. Ozone hourly profile of Libelium sensors against the reference method

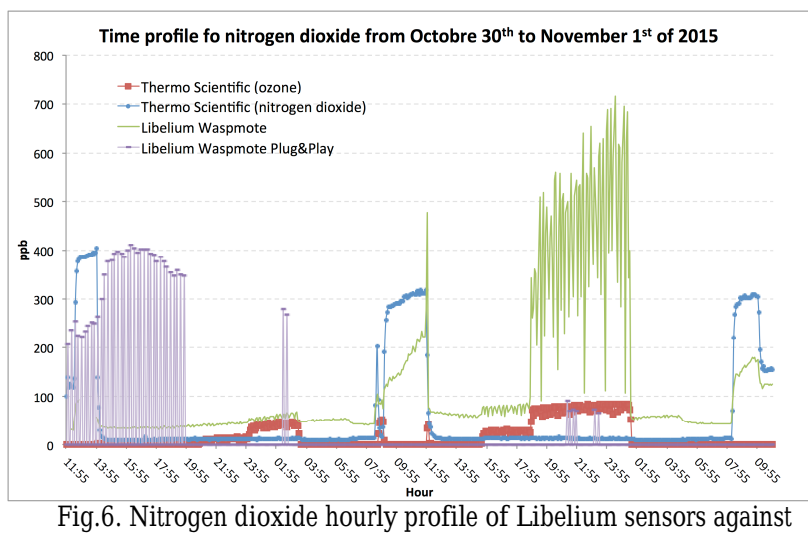
reference methods

Fig. 6 shows the nitrogen dioxide hourly values of the Libelium sensors against the reference method. The electrochemical method had no specificity for nitrogen dioxide whereas the solid-state sensor showed sensibility for $\mathrm{NO}_{2}$ and low cross sensibility for ozone.

Fig. 7 shows the hour profile of relative humidity. After a reconfiguration of the position of the sensors, Libelium Waspmote showed better agreement with reference data.

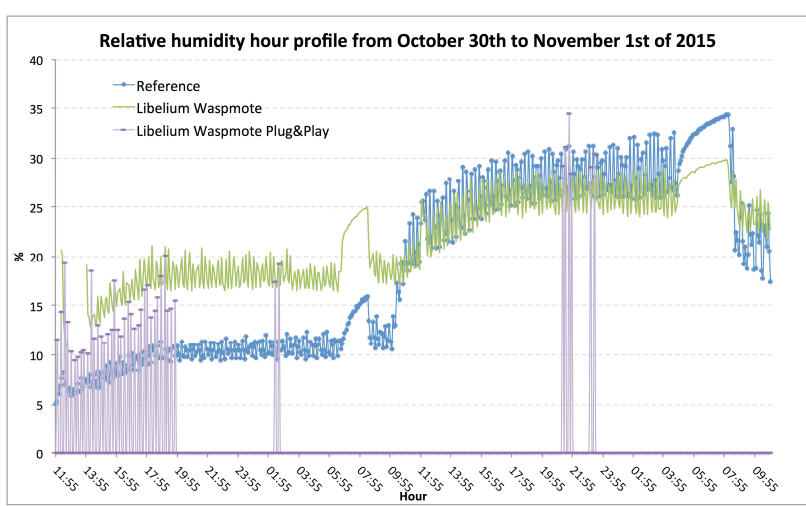

Fig.7. Hour profile for relative humidity of Libelium sensors and reference probe

The response of the sensors to temperature is shown in Fig.8.

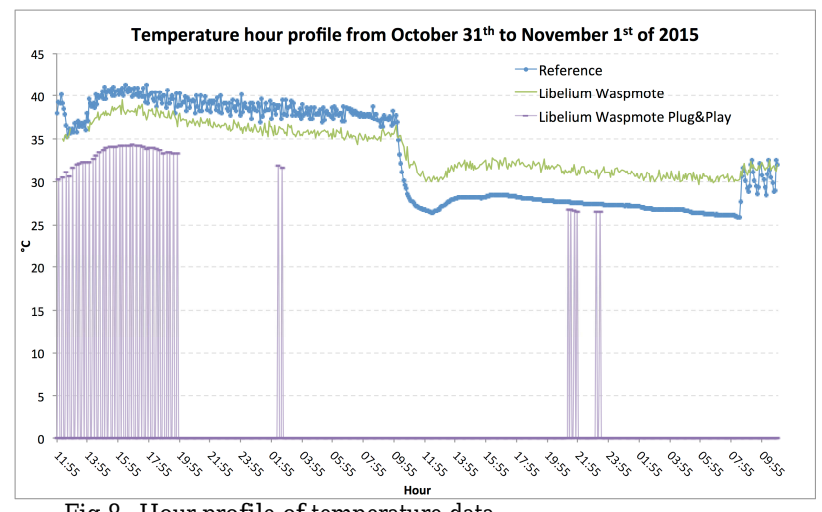

Fig.8. Hour profile of temperature data

With respect to Aeroqual Series 500 sensors, Fig. 9 shows the results of the test for $\mathrm{NO}_{2}$. At a first glance the four unit tested provided very similar measurements, although the offset can change after a span set-up. The sensors gave a very fast answer to changes in the $\mathrm{NO}_{2}$ concentration and the correlation was always positive. It is clear that a calibration must be performed previously to their use, and that their stability with time must be checked very often. The linear fit showed very good regression coefficients $\left(r^{2}>0.99\right)$.

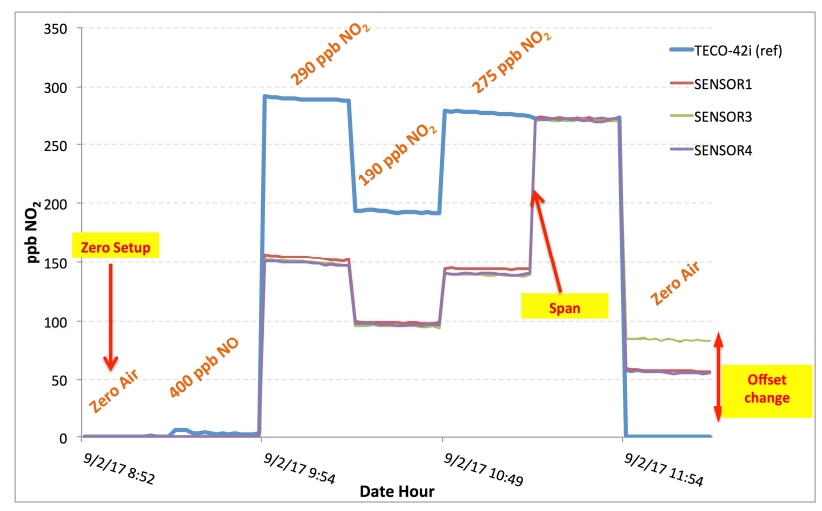

Fig.9. Test performed for the Areoqual sensors introducing $\mathrm{NO}_{2}$ in the calibration chamber.

\section{B. In field tests}

Fig. 10 and Fig. 11 illustrate the correlation of the sensors signals versus the measured concentration for $\mathrm{NO}_{2}$ and $\mathrm{O}_{3}$ by the Fernandez Ladreda (FL) station reference analyzers. As it can be seen, the correlation coefficient in both cases show that there is no relationship between the two variables, indicating that the two MICS solid state sensor are not providing a reliable information in real atmospheric conditions, even though the $\mathrm{O}_{3}$ solid state sensor gave acceptable results in the laboratory tests. 


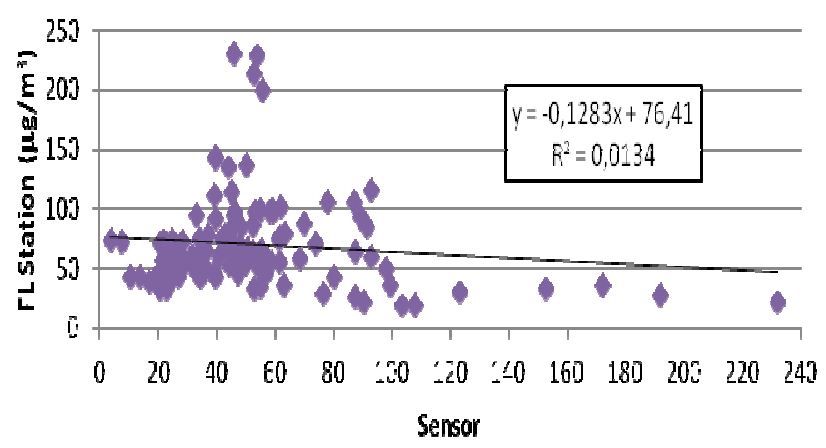

Fig.10. Waspmote signals vs. Fernández Ladreda analyzer data for $\mathrm{NO}_{2}$

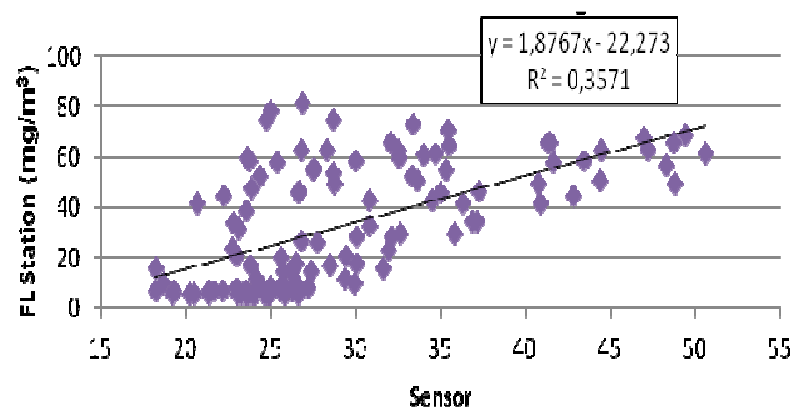

Fig.11. Waspmote signals vs. Fernández Ladreda analyzer data for $\mathrm{O}_{3}$

Time signal of the Libelium Plug and Sense versus that of the FL $\mathrm{NO}_{2}$ analyzer are shown in Fig. 12. It can be seen that low-cost sensors measurements did not match the observations form reference methods. A similar result (not shown) was obtained for $\mathrm{O}_{3}$. So the electrochemical sensors of the Plug and Sense device were not working properly as can be expected for an instrument that has not been specifically calibrated.

Finally, in Fig. 13 the correlation for the $\mathrm{NO}_{2}$ data of AQMesh sensor versus FL station analyzer are presented. The AQMesh data were post processed by a proprietary algorithm giving as result an acceptable correlation between sensor and reference data. During the in-field test the AQMesh $\mathrm{O}_{3}$ sensor was not working properly and is not possible to show the data.

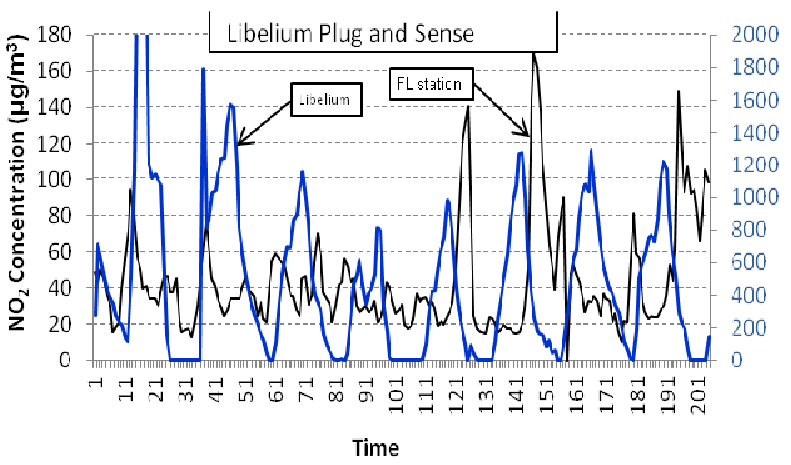

Fig.12. Plug and Sense signals vs. Fernández Ladreda analyzer data for $\mathrm{NO}_{2}$

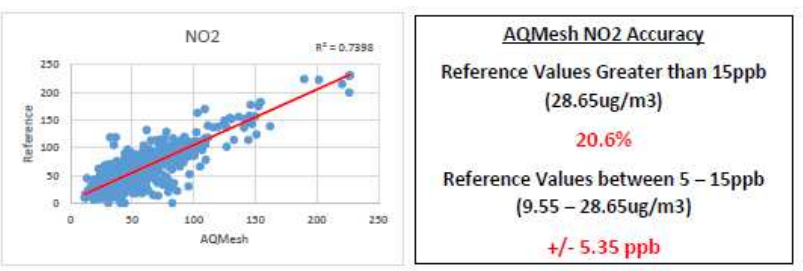

Fig.13. AQMesh signals vs. Fernández Ladreda analyzer data for $\mathrm{NO}_{2}$

\section{Discussion}

As several authors claim, low-cost sensors generally show good behavior in laboratory tests, although the results change dramatically when the devices are deployed in urban sites $[9,10]$. This is because the conditions of the urban atmosphere cannot be exactly reproduced in the laboratory, and sensors present cross sensitivity to other pollutants. Consequently, in-field calibrations of these devices, under the conditions in which they will be used, are essential for obtaining accurate readings in the urban atmosphere.

\section{CONCLUSIONS}

The following conclusions were extracted from this experiments:

- In the laboratory tests the evaluated instruments showed poor reproducibility for the same sensor.

- Sensitivity was not homogeneous and varied among the different instruments being in general low (in some cases it could be corrected with adjustments in the calibration)

- The instruments showed a very low specificity, being sensitive to gases that are not its measurement objective (cross sensitivity). Ozone was identified as an important interference for $\mathrm{NO}_{2}$ sensors.

- In general, the atmospheric parameters were measured correctly (because they must be used to correct the measurements).

- The conditions of the urban atmosphere (relative humidity, temperature and pressure) and the cross sensitivity to other pollutants affect the signals of the sensors.

- Each individual sensor behaves differently and thus, each unit requires the development and application of a specific calibration model to obtain reliable results with the low cost sensors devices.

\section{FURTHER WORK AND OUTLOOK}

The preliminary experiences summarized in this contribution highlight the limitations of commercial lowcost sensors and the difficulties of calibrating these devices with standard analytical procedures. We used the results from the analysis reported here as well as subsequent experiments to develop and advanced calibration framework based on machine learning algorithms (Fig. 14) with satisfactory results. 


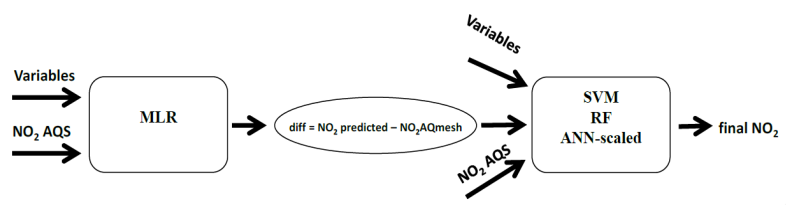

Fig.14. Flux diagram of the low-cost sensor measurements postprocessing [11]

As a consequence, we keep working on the development of statistical methods, such as linear regression (LR), multivariate linear regression (MLR) and artificial neural networks (ANN) to fit the signals and to obtain reliable results with the low cost sensors devices [11]. We are currently testing this analytical framework for small networks of self-made devices (Fig. 15) based on lowcost sensor deployed in real urban environments to confirm the robustness and performance of this technology.
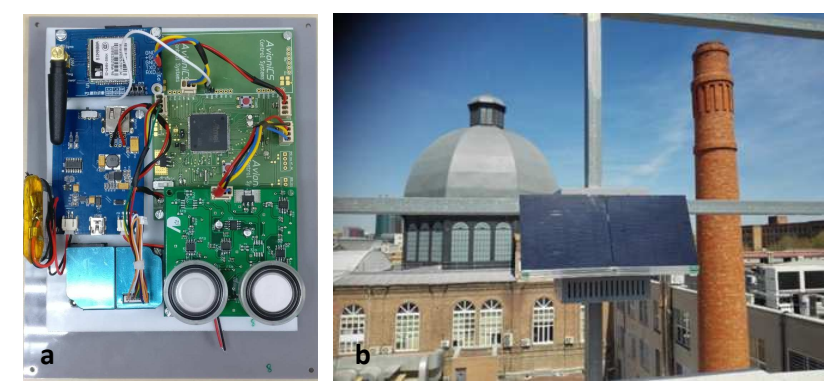

Fig.15. Low-cost sensor-based devices developed within the TECNAIRE-CM project

\section{ACKNOWLEDGMENT}

The presentation of the study has been made possible by the support Madrid Regional Research Plan though of AIRTEC-CM project (ref. S2013/MAE2972).

\section{REFERENCES}

[1] Directive 2008/50/EC of the European Parliament and the Council of 21 May2008 on ambient air quality and cleaner air for Europe.

[2] R. Borge, A. Narros, B. Artínano, C. Yagüe, F.J. Gomez-Moreno, D. de la Paz, C. Román-Cascon, E. Díaz, G. Maqueda, M. Sastre, C. Quaassdorff, C. Dimitroulopoulou, S. Vardoulakis. Assessment of micro-scale spatio-temporal variation of air pollution at an urban hotspot in Madrid (Spain) through an extensive field campaign, Atmospheric Environment, 140 (2016), 432-445.

[3] S. Moltchanov, I. Levy, Y. Etzion, U. Lerner, D. M. Broday, B. F.S. Moltchanov, I. Levy, Y. Etzion, U. Lerner, D.M. Broday, B. Fishbain, On the feasibility of measuring urban air pollution by wireless distributed sensor networks, Science of the Total Environment, 502 (2015), 537-547.

[4] L. Spinelle, M. Gerboles, M.G. Villani, M. Aleixandre, F. Bonavitacola, Field calibration of a cluster of low-cost available sensors for airquality monitoring. Part A: Ozone and nitrogen dioxide, Sensors and Actuators B, 215 (2015), 249-257

[5] H. Nakagawa, S. Okazaki, S. Asakura, K. Fukuda, H. Akimoto, S. Takahashi, S.Shigemori, An automated car ventilation system, Sens. Actuators B: Chem. 65 (2000), 133-137.

[6] M.C. Carotta, G. Martinelli, L. Crema, M. Gallana, M. Merli, G. Ghiotti, E. Traversa,Array of thick film sensors for atmospheric pollutant monitoring, Sens. Actua-tors B: Chem. 68 (2000), 1-8.

[7] C. Pijolat, C. Pupier, M. Sauvan, G. Tournier, R. Lalauze, Gas detection for auto-motive pollution control, Sens. Actuators B: Chem. 59 (1999), 195-202.

[8] A.C. Rai, P. Kumar, F. Pilla, A. N. Skouloudis, S. Di Sabatino, C. Ratti, A. Yasar, D. Rickerby, End-user perspective of low-cost sensors for outdoor air pollution monitoring, Science of the Total Environment 607-608 (2017) 691-705.

[9] N. Castell, F.R. Dauge, P. Schneider, M. Vogt, U. Lerner, B. Fishbain, D. Broday, A. Bartonova, Can commercial low-cost sensor platforms contribute to air quality monitoring and exposure estimates?, Environ. Int. 99 (2017) 293-302.

[10] C. Borrego, A.M. Costa, J. Ginja, M. Amorim, M. Coutinho, K. Karatzas, T. Sioumis, N. Katsifarakis, K. Konstantinidis, S. De Vito, E. Esposito, P. Smith, P. G, N. Andr, W. Reimringer, R.P. Otjes, O. Von Sicard, R. Pohle, B. Elen, Assessment of air quality microsensors versus reference methods : The EuNetAir joint exercise, 147 (2016) 246-263.

[11] J. M. Cordero, R. Borge, A. Narros, Using statistical methods to carry out in field calibrations of low cost air quality sensors, Sensors and Actuators B: Chem., 267 (2018), 245-254. 